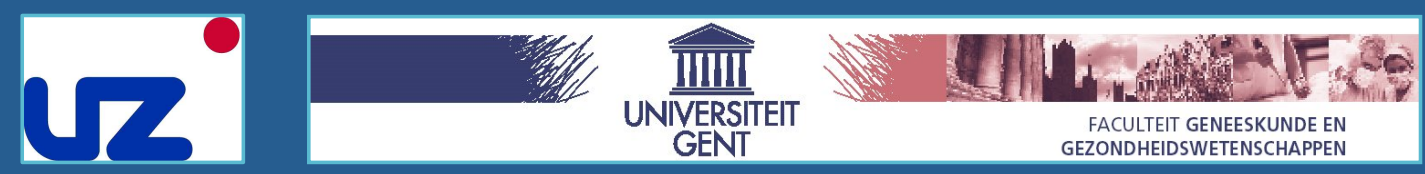

\title{
Bilateral BIS compatible with Loss Of Response to Name Calling: Comparison between Patients with and without a Brain Tumour
}

umcG

\author{
Wyler $B^{1}$, De Hert $S^{1,2}$, Absalom $A^{3}$, Struys MMRF ${ }^{1,3}$, Vereecke HEM ${ }^{3}$. \\ ${ }^{1}$ Department of Anesthesiology, Ghent University, Ghent, Belgium \\ ${ }^{1}$ Department of Anesthesiology, Ghent University, Ghent, Belgium
${ }^{2}$ Department of Anesthesiology, Ghent University Hospital, Ghent, Belgium \\ ${ }^{3}$ Department of Anesthesiology, University Medical Center Groningen, University of Groningen, the Netherlands
}

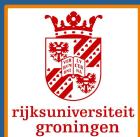

Introduction

The electroencephalogram during anaesthesia may be affected by brain tumour. We studied whether patients with unilateral or centrally located brain tumours have different BIS readings at Loss Of Response to Name Calling (LORNC) in healthy versus diseased hemispheres. We compared tumour patients with healthy control patients. We hypothesize that the presence of tumour evokes larger assymetry in bilateral BIS at LORNC compared to healthy control patients.

\section{Methods}

After EC approval and informed consent, 40 ASA 1 or 2 patients ( intracranial tumour ( standardized anaesthesia while measuring bilateral BIS using BIS VISTA ${ }_{\mathrm{XP} 4}$ monitor and bilateral sensor (Covidien,Dublin,Ireland)(figure 1) All data was collected using RUGloop II. (Demed, Temse, Belgium) Remifentanil was started at 3 or $5 \mathrm{ng} / \mathrm{ml}$ effect-site concentration ( ) (Minto Model) and maintained throughout the study. Propofol was set at $2 \mu \mathrm{g} / \mathrm{ml}$ ( $\quad$ ) (Schnider model, fixed time to peak effect) and increased with incremental steps of $0.5 \mu \mathrm{g} / \mathrm{ml}$. Every 15 seconds, the Observers' Assessment of Alertness and Sedation scale was determined until LORNC was observed. A t-test compared BIS compatible with LORNC between healthy versus diseased hemispheres within and between control and tumour patients. Statistical significance was set at $p<0.05$.

\section{$\underline{\text { Results }}$}

No demographic differences are found between groups. except for age. (table 1) Time to LORNC is significantly shorter in the tumour group (536s $( \pm 162)$ ) compared to control group (604s $( \pm 148))$. $\mathrm{Ce}_{\text {PROP }}$ at LORNC is significantly lower in the overall tumour group $(2.89 \mu \mathrm{g} / \mathrm{ml}( \pm 0.8))$ compared to control group $(3.32( \pm 0.86))$. Patients with tumour located centrally in the brain or in the right hemisphere have higher BIS at LORNC compared to control patients or patients with tumour in the left hemisphere. (figure 2) No statistical significant BIS asymmetry is found between left and right BIS at LORNC in any group. (table 2)

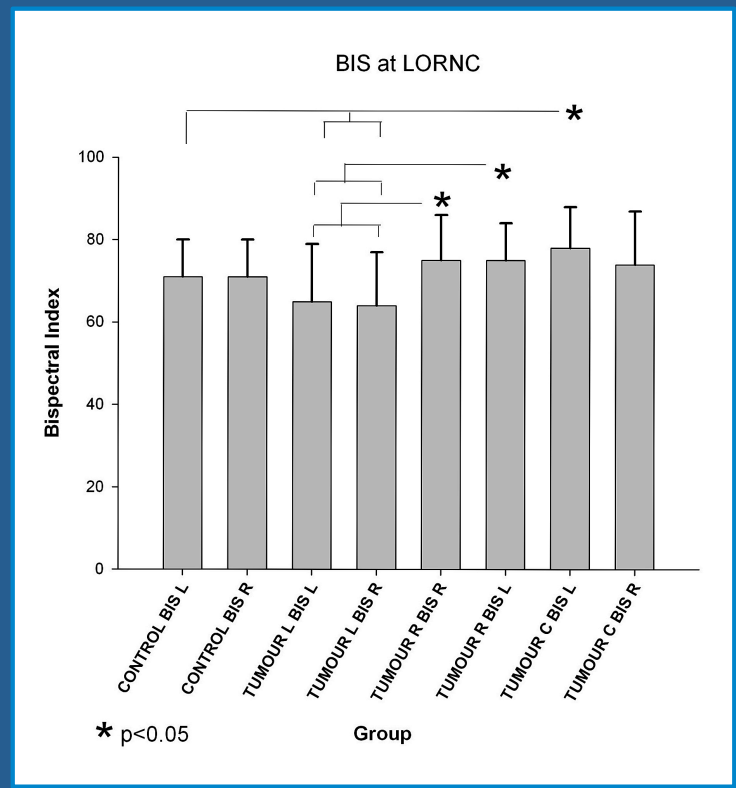

Figure 2

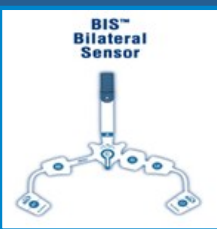

Figure 1

\begin{tabular}{c|c|c|c|c|}
$\begin{array}{c}\text { Demogra- } \\
\text { phics }\end{array}$ & $\begin{array}{c}\text { Age } \\
\text { (years } \pm \text { SD) }\end{array}$ & $\begin{array}{c}\text { Weight } \\
\text { (kg } \pm \text { SD) }\end{array}$ & $\begin{array}{c}\text { Height } \\
\text { (cm } \pm S D)\end{array}$ & $\begin{array}{c}\text { Time to } \\
\text { LOC (sec } \\
\pm S D)\end{array}$ \\
\hline $\begin{array}{c}\text { Control } \\
\text { group }\end{array}$ & $46 \pm 1 *$ & $76 \pm 15$ & $171 \pm 10$ & $604 \pm 148$ \\
\hline $\begin{array}{c}\text { Tumour } \\
\text { group }\end{array}$ & $50 \pm 16 *$ & $74 \pm 15$ & $172 \pm 10$ & $536 \pm 162$
\end{tabular}

Table 1

\begin{tabular}{|c|c|c|}
\hline LORNC & $\begin{array}{c}\text { BIS left (mean } \\
\pm S D)\end{array}$ & $\begin{array}{c}\text { BIS right } \\
\text { (mean } \pm \text { SD) }\end{array}$ \\
\hline Control group & $71 \pm 9$ & $71 \pm 11$ \\
\hline Left Tumour group & $65 \pm 14$ & $64 \pm 14$ \\
\hline Right Tumour group & $75 \pm 9$ & $75 \pm 11$ \\
\hline $\begin{array}{c}\text { Central Tumour } \\
\text { group }\end{array}$ & $79 \pm 10$ & $74 \pm 13$ \\
\hline
\end{tabular}

Table 2

\section{Conclusions}

No difference is found in BIS assymetry between individuals with or without brain tumour. In both groups, unilateral BIS monitoring is equally effective for detecting LORNC, compared to bilateral BIS.

The higher BIS values at LORNC in some tumour patients are mainly attributable to differences in

CePROP at LORNC rather than to tumour related causes. 